\title{
Analysis of DNA methylation in chondrocytes in rats with knee osteoarthritis
}

\author{
Xinxin Wang ${ }^{1,2}$, Dezhi Tang ${ }^{2 *}$, Peng Shen ${ }^{1,2}$, Hao Xu², Hongfu Qiu', Tao Wu ${ }^{1}$ and Xiang Gao ${ }^{1 *}$
}

\begin{abstract}
Background: Knee osteoarthritis (KOA) is a degenerative knee disease commonly found in the ageing population. DNA methylation works with histone acetylation to participate in aging. Alterations of DNA methylation may involve the joint chondrocyte degeneration in KOA. The aim of this study is to detect DNA methylation changes in chondrocytes of rats with KOA.

Methods: The rat KOA model was established with the Hulth method $(n=10)$, while rats receiving sham operation served as the control $(n=10)$. At 16 weeks after modeling, the knee joint tissue was collected from half of the rats in each group for Micro-CT scanning, Haematoxylin\& Eosin (HE) staining, ABH/OG staining, immunohistochemistry for Bax, BCl-2 and Fas, and TUNNEL staining. Meanwhile, the articular cartilage was collected from the other half to detect promoter methylation in target genes with the MethylTarget approach.
\end{abstract}

Results: Micro-CT scanning, HE staining, ABH/OG staining, immunohistochemistry, and TUNNEL staining all showed more severe cartilage injury in the KOA group than in the control group, indicating successful establishment of KOA model. The methylation rate in the KOA group was significantly decreased for C/ebpa-2 (within a CpG island -452 bp to the initiation codon on chromosome 191,363,511), Cdk2 (within a CpG island -55 bp to the initiation codon on chromosome 7

3,132,362), Bak1 (within a CpG island 6452 bp to the initiation codon on chromosome 20 5,622,277), and Fas (within a CpG island on the entire chromosome 1 gene), compared with the sham group ( $P=0.005,0.008,0.022$ and 0.027 , respectively).

Conclusion: The chondrocyte apoptosis and significantly reduced methylation levels of C/ebpa-2, Cdk2, Bak1, and Fas may participate in the pathogenesis of KOA. However, the exact mechanisms remain to be determined.

Keywords: Knee osteoarthritis, C/ebpa, Cdk2, Fas, Bak, Methylation

\section{Background}

Knee osteoarthritis (KOA) is a degenerative knee disease commonly found in the ageing population. It is usually derived from pathology of the cartilage, subchondral bone and synovial membrane of the knee joint. KOA is clinically characterized as progressive knee pain, swelling, stiffness, and restricted joint range of motion, and even joint deformity in serious conditions, resulting in loss-of-function of the joint, largely affecting the life quality of patients and posing a great economic burden [1]. Currently, there is no well treatment for KOA. All therapeutic approaches are aimed at ameliorating symptoms and improving joint functions. $\mathrm{KOA}$ is a multi-

\footnotetext{
*Correspondence: dztang702@126.com; gaoxiang19710312@sina.com ${ }^{2}$ Spine Research Institute, Shanghai University of Traditional Chinese Medicine, Shanghai 200032, China

'Department of Surgery, Huadong Hospital Affiliated to Fudan University, Shanghai 200040, China
}

factorial disease. Apart from living style and healthy conditions, other factors like genetic aberrations and environmental factors also contribute to its occurrence. Changes in genetic modulation in cartilage have been implicated in the pathogenesis and progression of KOA. DNA methylation is one such player that has been receiving more and more attention. DNA methylation is a typical epigenetic modification of DNA to modify gene expression, which involves a process of transference of a methyl group on S-adenosyl methionine to the 5th atom of the cytosine ring under the catalysis effect of DNA methyltransferase, forming 5-methylcytosine. DNA methylation plays critical roles in embryo development, $\mathrm{X}$ chromosome inactivation, regulation of gene expression, gene imprinting and silencing, and tumorigenesis [2]. In addition, it works with histone acetylation to participate in aging. Alterations of DNA methylation 
may involve the joint chondrocyte degeneration in the elderly KOA patients. In this study, methylation was analyzed in KOA rats for 31 genes (C/ebpa, Cdk, Bak, Bax, Fas, Bcl, Tnfaip3, Tnfsf11, Il6r, Rel, Ikzf3, Irf5, Kdm4b, Aire, Nr3c1, Ptpn2, Mlh1, Irf8, Ifngr2, Nfkbie, Irak1, and Kdm6b, etc.) selected by searching the literatures [3-19]. These genes are directly or indirectly related to the metabolism of bone or cartilage through a common mechanism. By detecting the changes in methylation level of these genes, we hope to clarify the relationship between methylation alterations and KOA pathogenesis.

\section{Methods}

\section{Animals}

Twenty SPF-grade male SD rats (8 weeks, 180-200 g, Charles River Laboratories, Beijing, China) were randomly assigned into sham-operation and KOA model groups ( $n=10$ in each group). The rats were housed in groups of 5 in cages under room temperature of $21-22{ }^{\circ} \mathrm{C}$ with a $12 \mathrm{~h}$ light/dark cycle and free access to food and water. KOA modeling was performed after 1-week habituation. After fasting for $12 \mathrm{~h}$, KOA model was established in the rats with the Hulth method [20]. Briefly, after anesthesia with intraperitoneal injection of $10 \%$ chloral hydrate, a longitudinal incision of $10 \mathrm{~cm}$ was made on skin at the inner side of the right hind knee of rat placed in a supine position. The medial collateral ligament was cut to open up the joint cavity, and medial meniscus was resected, then the anterior and posterior cruciate ligaments were cut. The anteriordrawer test was used to confirm rupture of the ligaments. Efforts were made to avoid artificial injury to articular cartilage. Sutures were made layer-bylayer. Rats in the sham group received only the same operation of skin incision. After surgery, chlortetracycline ointment was applied to the incision site and the surroundings to prevent infection.

\section{Sample preparation}

At 16 weeks after modeling, rats in each group were sacrificed by injection with pentobarbital sodium at a dose of $0.2 \mathrm{ml} / 100 \mathrm{~g}$. The articular cartilage was collected from 5 rats in each group and stored in formalin until use for methylation analysis. Meanwhile, the knee joint of the right hind limb was collected from the left rats, fixed in formalin for $48 \mathrm{~h}$, and stored in $75 \%$ ethanol at room temperature until Micro-CT scanning, Haematoxylin\& Eosin (HE) staining, orange G (ABH/ OG) staining, immunohistochemistry and TUNNEL staining.

\section{Sample processing}

After Micro-CT scanning (Scanco, vivaCT80), the knee joint tissue was decalcified in 14\% EDTA ( $\mathrm{pH} 7.40 \pm 0.05$ ) for 4 weeks with replacement of the decalcification medium every 2-3 days, followed by dehydration, wax immersing and embedding. Then the tissue was cut at $5 \mu \mathrm{m}$, and subsequently $\mathrm{HE}$ and $\mathrm{ABH} / \mathrm{OG}$ staining, immunohistochemistry, and TUNNEL staining were conducted.

The articular cartilage underwent MethylTarget analysis of methylation of $\mathrm{CpGIsland}$ in the promoter region of 31 genes including C/ebpa, Cdk, Bak, Bax, Fas, Bcl, Tnfaip3, Tnfsf11, Il6r, Rel, Ikzf3, Irf5, Kdm4b, Aire, Nr3c1, Ptpn2, Mlh1, Irf8, Ifngr2, Nfkbie, Irak1, Kdm6b, etc. The MethylTarget test is an approach for DNA methylation level mapping following bisulfite treatment and bioinformatics data analysis, based on the second-generation high throughput sequencing platform $[21,22]$.

\section{Bisulfite conversion and multiplex amplification}

DNA methylation level was analyzed by MethylTargetTM, an NGS-based multiple TargetedCpG methylation analysis method.Specifically, the genomic regions of interest were analyzed and transformed to bisulfiteconverted sequences by geneCpG software. PCR primers (Table 1) were designed using the Methylation Primer software based on the bisulfate converted DNA.

Genomic DNA (400 ng) was treated with sodium bisulfite using an EZ DNA Methylation ${ }^{\text {mit-GOLD Kit }}$ (Zymo Research) according to the manufacturer's protocols. Multiplex PCR was performed with an optimized combination of primers. A $20 \mu \mathrm{l}$ PCR reaction mixture was prepared for each reaction, which included $1 \times$ reaction buffer (Takara), $3 \mathrm{mM} \mathrm{Mg} 2+, 0.2$ mMdNTP, $0.1 \mu \mathrm{M}$ of each primer, $1 \mathrm{U}$ HotStarTaq polymerase (Takara) and $2 \mu \mathrm{l}$ template DNA.The PCR program included $95{ }^{\circ} \mathrm{C}$ for $2 \mathrm{~min} ; 11$ cycles of $94{ }^{\circ} \mathrm{C}$ for $20 \mathrm{~s}, 63{ }^{\circ} \mathrm{C}$ for $40 \mathrm{~s}$ with a decreasing temperature step of $0.5{ }^{\circ} \mathrm{C}$ per cycle, $72{ }^{\circ} \mathrm{C}$ for $1 \mathrm{~min}$; then $24 \mathrm{cy}$ cles of $94{ }^{\circ} \mathrm{C}$ for $20 \mathrm{~s}, 65{ }^{\circ} \mathrm{C}$ for $30 \mathrm{~s}, 72{ }^{\circ} \mathrm{C}$ for $1 \mathrm{~min}$; and finally $72^{\circ} \mathrm{C}$ for $2 \mathrm{~min}$.

\section{Index PCR}

PCR amplicons were diluted and amplified using indexed primers. Specifically, a $20 \mu \mathrm{l}$ mixture was prepared for each reaction, including $1 \times$ reaction buffer (NEB Q5TM), $0.3 \mathrm{mMdNTP}, 0.3 \mu \mathrm{M} F$ primer, $0.3 \mu \mathrm{M}$ index primer, $1 \mathrm{U}$ Q5TM DNA polymerase (NEB) and $1 \mu \mathrm{L}$ diluted template. The PCR program was $98{ }^{\circ} \mathrm{C}$ for $30 \mathrm{~s} ; 11$ cycles of $98{ }^{\circ} \mathrm{C}$ for $10 \mathrm{~s}, 65{ }^{\circ} \mathrm{C}$ for $30 \mathrm{~s}, 72{ }^{\circ} \mathrm{C}$ for $30 \mathrm{~s}$; and $72{ }^{\circ} \mathrm{C}$ for $5 \mathrm{~min}$. PCR products (170 bp-270 bp) were separated by agarose electrophoresis and purified using QIAquick Gel Extraction kit (QIAGEN). 
Table 1 Primers of target genes

\begin{tabular}{|c|c|c|}
\hline $\mathrm{NO}$ & Primer Name & sequence \\
\hline \multirow[t]{2}{*}{1} & Aire_F & ATAGTATTAGATATTTAAGGGAGAAGGGAA \\
\hline & Aire_R & ACCTAAAACTTATCCTCAAAAACCAC \\
\hline \multirow[t]{2}{*}{2} & Atm_F & GGTTITATTGGYGGTGTTGAAT \\
\hline & Atm_R & CACTCRCTCCCCTCAAAACATT \\
\hline \multirow[t]{4}{*}{3} & Bak1_1F & GTGGAYGAGAGTAGTITAAGTGGTG \\
\hline & Bak1_1R & САТTTCTTСCCTAAACCATTAACC \\
\hline & Bak1_2F & GGAGTTGATTITTGTYGGGAGTT \\
\hline & Bak1_2R & AACTCCTAACTACTCCCRAAACCAA \\
\hline \multirow[t]{2}{*}{4} & Bax_1F & GTATGYGTGAATTAAATGGTAGAGGTIT \\
\hline & Bax_1R & TAATTCTCCRCCTCCCRCCTC \\
\hline \multirow[t]{4}{*}{5} & $\mathrm{BCl} 2 \_1 \mathrm{~F}$ & GTITAGATIITAGGGGAGAGATATGTT \\
\hline & $\mathrm{BCl} 2 \_1 \mathrm{R}$ & ACACAATACRCRAACTACTCCTTAAACAC \\
\hline & $\mathrm{BCl} 2 \_2 \mathrm{~F}$ & GGGYGTTAGGTGTAGTTGATTGGATA \\
\hline & $\mathrm{BCl} 2 \_2 \mathrm{R}$ & ССТАACATCTTСТССТTССАACСT \\
\hline \multirow[t]{2}{*}{6} & $\mathrm{Cdk} 2 \_2 \mathrm{~F}$ & AAATTGTTAAGAGTTGAGTITGTTG \\
\hline & Cdk2_2R & TACCCTCTCCAATCTTCTCCAC \\
\hline \multirow[t]{8}{*}{7} & Cebpa_22F & GGATAGAAGGGGTTTGGTGAG \\
\hline & Cebpa_22R & AACCATTACACTAAAAAATCTTAACCTTAC \\
\hline & Cebpa_2F & TGGAAAGTTATAAGAGAAGGTAGGTIT \\
\hline & Cebpa_2R & CCACCCAATACCCCAACTC \\
\hline & Cebpa_3F & GTAAGGTTAAGAAGTYGGTGGATAAGA \\
\hline & Cebpa_3R & CCTTAACCAAAAAACTCTCAAACAAC \\
\hline & Cebpa_F & GGTIIITAGAGTAGTAGGGYGTTAGGA \\
\hline & Cebpa_R & CCRAAACATTTAACTAAAAACTCCAC \\
\hline \multirow[t]{2}{*}{8} & Cflar_F & GGTITITGAGATITITAGGGTTATTAG \\
\hline & Cflar_R & СТCСATTTATAAACCCCAAAACA \\
\hline \multirow[t]{2}{*}{9} & Esr1_F & AAGATGTTATGGAGAGGGTITTG \\
\hline & Esr1_R & AAAACCCCCAAACTATTAACACC \\
\hline \multirow[t]{2}{*}{10} & Fas_1F & GAGTTGTGTGGGTGTTAGTTTGTG \\
\hline & Fas_1R & AACTACATATAAACATCTCTCATCACCAA \\
\hline \multirow[t]{2}{*}{11} & Icam1_F & TGGGGAGTTATTAAGAYGTITTAGTAGTTA \\
\hline & Icam1_R & САTTCAAAAATATCCСТСТСССТА \\
\hline \multirow[t]{2}{*}{12} & ICOSLG_F & AGAGTGGAGAGTTGTAGTTGTTGG \\
\hline & ICOSLG_R & CCCTACCCAACATCAAACTAAAC \\
\hline \multirow[t]{2}{*}{13} & Ifngr2_F & GTGGGTGTYGTTGGGAGTT \\
\hline & Ifngr2_R & ССТTCAACAAATCTCCCTAACA \\
\hline \multirow[t]{2}{*}{14} & Ikzf3_F & GGGTTGTAGTTGTTGTTTAGGTTT \\
\hline & Ikzf3_R & CAAAATTCCTCAAACTTAACATTCAA \\
\hline \multirow[t]{2}{*}{15} & $\| 6 r_{-} F$ & GATTAGGATGTAGTTGAGTAAGATTTGT \\
\hline & $\| 6 r \_R$ & ACCAACCTAAAACTAACCCACCTATACT \\
\hline \multirow[t]{2}{*}{16} & Irak1_F & TGGATTAAGGTITTGGAGTTGA \\
\hline & Irak1_R & CCCATCCCTAAAATCCCTAAAA \\
\hline \multirow[t]{2}{*}{17} & Irf5_F & GGAGTAGGGAGGATGTTTATTGG \\
\hline & Irf5_R & AACTACTACCAAACCACCRCTCC \\
\hline
\end{tabular}

Table 1 Primers of target genes (Continued)

\begin{tabular}{|c|c|c|}
\hline & Irf8_F & TAGTTGGGTTITTTGGGAAAGTAA \\
\hline & Irf8_R & ACCCCRCCCTATCTATAAAAACAAA \\
\hline \multirow[t]{4}{*}{18} & Kdm4b_2F & GGGTTGGTTGTGTGTATITTA \\
\hline & Kdm4b_2R & СТССССТСATCAACACCTAAC \\
\hline & Kdm4b_4F & AAGGGTGGAGTTYGGAGTATATAAGA \\
\hline & Kdm4b_4R & TCAAAATACACACAACCAACCC \\
\hline \multirow[t]{4}{*}{19} & Kdm6b_2F & GAGTATATITIAGGTITGGTAGGTAGGG \\
\hline & Kdm6b_2R & CRCCAAAAACCCTTCTACCTTTAT \\
\hline & Kdm6b_F & GGGAAGGTTAGGGAAGGGA \\
\hline & Kdm6b_R & ACACRCATTTAACCAACACCCAC \\
\hline \multirow[t]{4}{*}{20} & Mlh1_1F & GTTGGGAAGGTGGTTAGGA \\
\hline & Mlh1_1R & CCAATTTTCAATCATCTCTTTAATAACA \\
\hline & Mlh1_2F & GGTGTATTTGTTYGGGTGATTTG \\
\hline & Mlh1_2R & CRCAAACTCCACCACCAAATAAC \\
\hline \multirow[t]{2}{*}{21} & Nfkbie_F & GGGATTAGGGTTAGTGGGATT \\
\hline & Nfkbie_R & AAAACCCTTCAACTACCCAAAA \\
\hline \multirow[t]{4}{*}{22} & Nr3c1_23F & GGTAGTTAGAGTITITGAGGGGATAGTT \\
\hline & Nr3c1_23R & CTAACCCTCTCCTCTACRCTCCC \\
\hline & $\mathrm{Nr3c1 \_ 24F}$ & AAGTTTGGGTTGTAGGTTGTGAG \\
\hline & Nr3c1_24R & CRCCACCATCCCTAACCC \\
\hline \multirow[t]{2}{*}{23} & Nr3c1_F & GATIITAAGAGGTTAGGTAGAGGAGAT \\
\hline & Nr3c1_R & СССТСТACСТCATACCATAAACTAAA \\
\hline \multirow[t]{4}{*}{24} & Ppara_2F & GGTGTTAGGGTGGGTGTGG \\
\hline & Ppara_2R & TACCCCCTACRCTATCAATTAACAA \\
\hline & Ppara_F & TGAGGTGGGTGGATAGGG \\
\hline & Ppara_R & CTCCAACCCACAAAACAACTAC \\
\hline \multirow[t]{2}{*}{25} & Ptpn2_F & GGAGGTTGTTGGTTTTGAAGG \\
\hline & Ptpn2_R & CTAACCCCATCAAAAAACTCTCTC \\
\hline \multirow[t]{2}{*}{26} & Rel_F & GAATAGGTGTTAATTAGTAAGGGAAGG \\
\hline & Rel_R & CAACCTTATTTTCCСТCTATATCTACATT \\
\hline \multirow[t]{2}{*}{27} & Tnfaip3_F & GGATGTGAYGTGGAAGGTAGTTTT \\
\hline & Tnfaip3_R & AAAACTACAAACTAAACAATTCCCTIT \\
\hline \multirow[t]{2}{*}{28} & Tnfsf11_F & AGGAGATGGGTAGTTGTTTTGG \\
\hline & Tnfsf11_R & AATCCTAAAACCAAACTCAATTTCC \\
\hline \multirow[t]{2}{*}{29} & Traf6_F & GGAGATATTTGATTYGGAGTGTTG \\
\hline & Traf6_R & CAACRACACRTCCTTATCCCTT \\
\hline \multirow[t]{2}{*}{30} & Tyk2_F & GATGATTAATAGGAATGTAGGATYGTG \\
\hline & Tyk2_R & AАCCTCСTCCCTACCAACTTC \\
\hline \multirow[t]{2}{*}{31} & Wnt2_F & TGAAGAGTTGATTITAGGGGTGA \\
\hline & Wnt2_R & AACTTTATCAATAAATCTCACCACTAACC \\
\hline
\end{tabular}

\section{Sequencing}

Libraries from different samples were quantified, pooled together, and used for sequencing on the IlluminaMiSeq platform according to the manufacturer's protocols. 
Sequencing was performed with a 2x300bp paired-end mode.

\section{Statistics}

Quality control of sequencing reads was performed by FastQC. Filtered reads were mapped to genome by Blast after reads recalibration with USEARCH. All data are presented as mean \pm SD and were analyzed with Independent samples $\mathrm{t}$-test or $\mathrm{U}$ test to assess differences between groups. $P<0.05$ was considered as statistically significant. Methylation and haplotype were analyzed using Perl script. Statistics were performed by t-test and ANOVA. Graphs were drawn with GraphPad Prism 5.0.

\section{Results}

\section{Micro-CT, $\mathrm{HE}$ and $\mathrm{ABH} / \mathrm{OG}$ staining}

The reconstructed 3-dimensional image of the articular cartilage by Micro-CT showed a smooth surface of the articular cartilage with no osteophyte formation in the sham group (Fig. 1a1). The coronal section image (Fig. 1a2) showed thick, uniformly aligned trabeculae. However, the KOA group showed cartilage defects such as a rough surface, focal surface fissures and flaking, and exposure of the subchondral bone (Fig. 1b1). Round or oval-shaped osteophyteswere formed along the lining of joint. The coronal section image (Fig. 1b2) showed a thin cartilage layer, small, disorganized trabeculae, and subchondral bone cystic degeneration.

HE staining revealed a smooth surface of cartilage in the sham group, with even coloration of cartilage matrix into light pink and blue chondrocyte nuclei (Fig. 2). The cartilage had clear structural layers and a tidal line. The

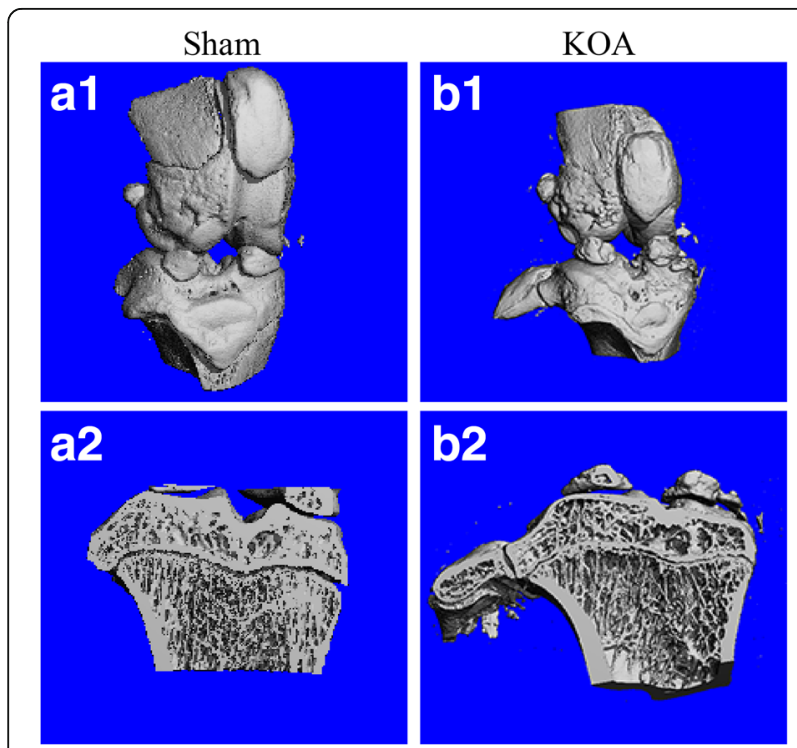

Fig. 1 Images of Micro-CT scanning of the rat knee joint. $\mathbf{a} \mathbf{1}$ and $\mathbf{b} \mathbf{1}$ are reconstructed 3-dimensional images; $\mathbf{a} \mathbf{2}$ and $\mathbf{b} \mathbf{2}$ are images of coronal sections out layer of cartilage was composed of flat chondrocytes, the middle layer composed of round uniformly-aligned chondrocytes, and inner and calcification layers composed of proliferating chondrocytes. Meanwhile, the cartilage matrix was evenly stained into blue by ABH/OG staining (Fig. 3). In the KOA model group, HE staining a thin cartilage layer, superficial fibrillation, necrosis of chondrocytes, unclear nucleus and cytoplasm, a rough surface with fissures and flaking, portional loss of cartilage, exposure of the subchondral bone, uneven coloration, unclear structural layers and tidal line, proliferation of chondrocytes in the outlayer, disordered cell alignment, appearance of cell clusters, and blood vessels passing through the tide line. Meanwhile, weak and negative staining was seen by $\mathrm{ABH} /$ OG staining, with clear fibrillation (Fig. 3). These results suggest the successful modeling of KOA in rats with the Hulth method.

\section{Immunohistochemistry and TUNNEL staining}

Immunohistochemistry for apoptotic proteins $\mathrm{Bax}, \mathrm{Bcl}-2$, and Fas revealed brown positive cells. Six view fields were randomly selected under a microscope to count the positive cells and calculate the positive rate. Results showed significantly increased levels of Bax, Bcl-2, and Fas in the KOA group than in the sham group (Fig. 4, Table 1). TUNNEL staining revealed a significantly higher apoptosis rate in the KOA group than in the sham group (Fig. 4, Table 2).

\section{Methylation analysis}

A significantly decreased methylation rate was detected in the KOA group forC/ebpa-2 (within a CpG island $-452 \mathrm{bp}$ to the initiation codon on chromosome 1 91,363,511), Cdk2 (within a CpG island -55 bp to the initiation codon on chromosome 73,132,362), Bak1 (within a CpG island 6452 bp to the initiation codon on chromosome 20 5,622,277), and Fas (within CpG islands on the entire chromosome 1 gene), compared with the sham group (Fig. 6, Table 3).

\section{Discussion}

KOA is a multifactorial disease with multiple contributors including genetic aberrations and environmental factors apart from life style and healthy conditions. Pathologically, KOA mainly involves degeneration of the cartilage and alterations of the cartilage matrix. Abnormalities of gene regulation in chondrocytes may be implicated in the pathogenesis and progression of KOA. DNA methylation is a typical form of epigenetic modification of DNA, and it works with histone acetylation to affect the aging process. Abnormal epigenetic modification is closely associated with KOA pathology as a result of environmental changes or aging, and affects KOA occurrence and progression via epigenetic modification. As epigenetic modification is a reversible process, it is 

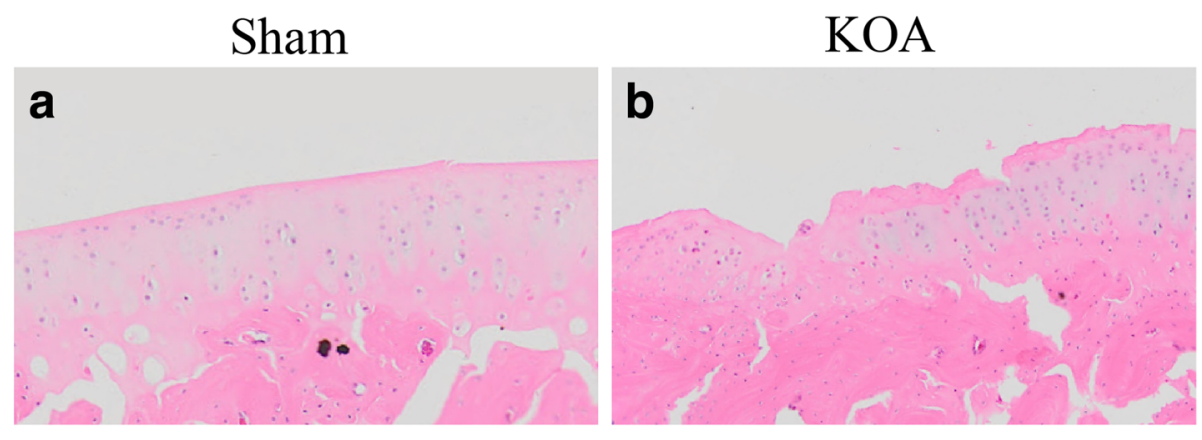

Fig. 2 HE staining of the knee joint. a, sham group; b, KOA model group

reasonable to discover its role in $\mathrm{KOA}$ pathology, in which it slows down the development or even prevents the occurrence of KOA. In this study, we selected 31 KOA-related genes by searching literatures, and sequence their methylated sites, in order to clarify the relationship between gene methylation and KOA.

Results of Micro-CT scanning (Fig. 1), HE staining (Fig. 2), ABH/OG staining (Fig. 3), immunohistochemistry (Fig. 4) and TUNNEL staining (Fig. 5) all confirmed the successful establishment of $\mathrm{KOA}$ model in rats. In addition, the methylation rate in the KOA group was significantly lower than that in the sham group for genes C/ebpo-2 (within a CpG island -452 bp to the initiation codon on chromosome $191,363,511$ ), Cdk2 (within a CpG island -55 bp to the initiation codon on chromosome $73,132,362$ ), Bak1 (within a CpG island 6452 bp to the initiation codon on chromosome 20 5,622,277), and Fas (within a CpG island on the entire chromosome 1 gene) (Fig. 6, Table 2). The decreased methylation in KOA chondrocytes may cause increased expression of these genes, which would further induce chondrocyte injury or apoptosis, leading to the pathogenesis and progression of KOA.

Aggravated chondrocyte injury or apoptosis occurs upon KOA onset [23]. Cartilage does not contain blood vessels. It has a low regeneration capacity and is therefore hard to repair after injury. When cartilage injury is so severe that the subchondral bone is damaged, rupture of small blood vessels would occur within the marrow cavity of cancellous bone. Then the blood forms a layer of fibrous clot on the surface of damaged cartilage area. In the absence of an external overload, the undifferentiated mesenchymal cells in bone marrow would move into this clot, whereby they differentiate into chondroblasts and proliferate into cells with chondrocyte morphology and typical features, in most cases fibrocartilage. Generally, an injury with a diameter $<3 \mathrm{~mm}$ can repair through generation of a hyaline cartilage, while a larger area of injury would repair by fibrous tissue [24]. Under normal conditions, C/ebp $\alpha$ can modulate the differentiation and proliferation of bone marrow mesenchymal stem cells into chondrocytes, and inhibit apoptosis of chondrocytes.

Here we found decreased methylation in promoter regions of $\mathrm{C} / \mathrm{ebp} \alpha$ and $\mathrm{Cdk} 2$ genes, which may induce overexpression of them. C/ebpa is present in multiple cell types, and participates in cell proliferation, differentiation, development, and tumorigenesis [25]. C/ebpo acts mainly to induce cell differentiation and inhibit cell proliferation [26]. The cyclin-dependent kinase Cdk2 can stimulate meiosis of germ cells and the G1-S transition during the mitotic cycle by interacting with cyclin $\mathrm{E}$ in early phases of DNA synthesis [27], thereby acting as a rate-limiting enzyme during cell proliferation [28]. Cdk2 activity peaks at $S$ and G2 phases. In late phase of DNA replication, Cdk2 is activated by cyclin A2 to drive the S-G2 transition [29]. Wang $\mathrm{H}$ et al. found that C/ebpo directly interacts with $\mathrm{Cdk} 2$ to inhibit cell proliferation. In

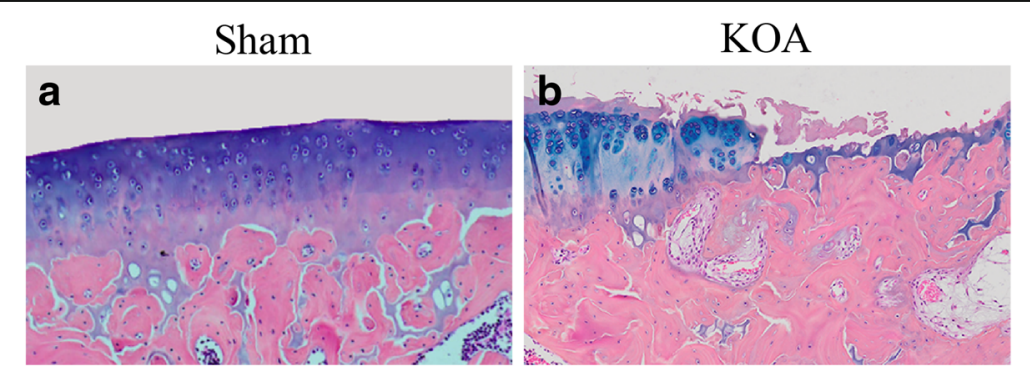

Fig. $3 \mathrm{ABH} / \mathrm{OG}$ staining of the knee joint. $\mathbf{a}$, sham group; $\mathbf{b}, \mathrm{KOA}$ model group 


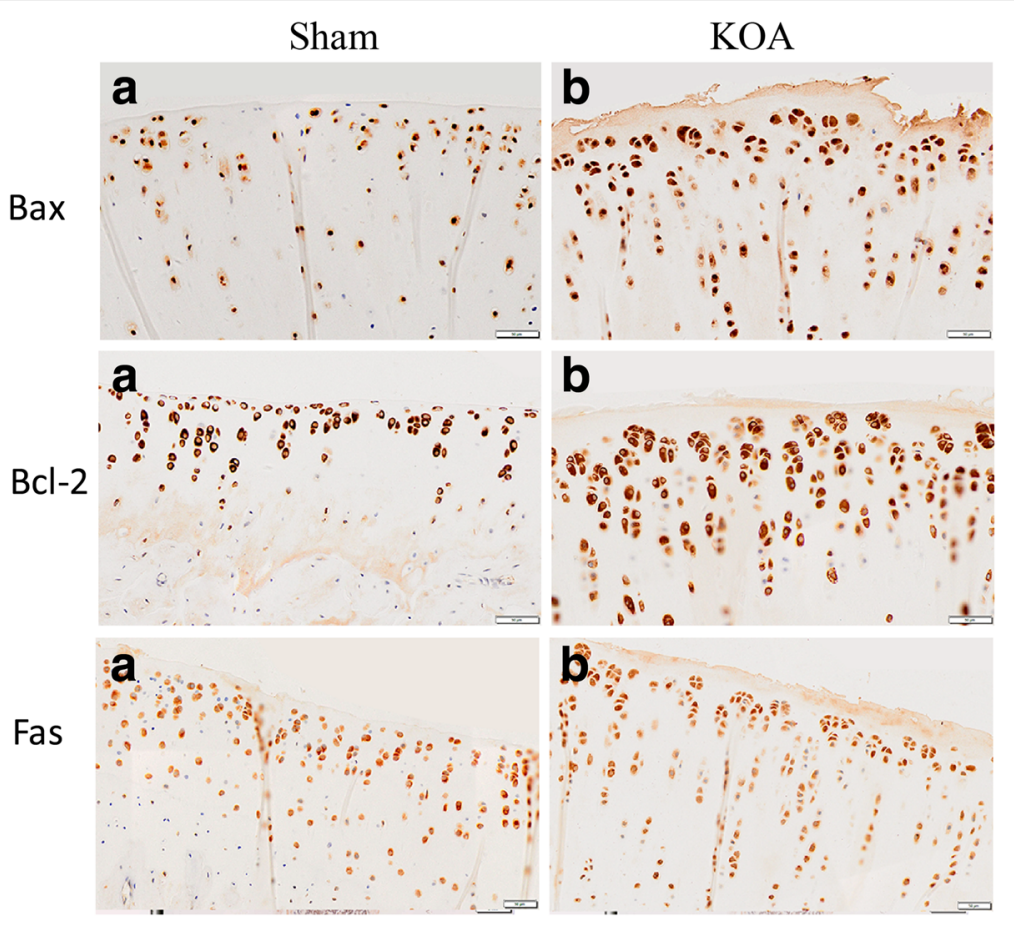

Fig. 4 Immunohistochemistry of $\mathrm{Bax}, \mathrm{BCl}-2$ and Fas in the knee joint. a, sham group; $\mathbf{b}$, KOA model group

C/ebp $\alpha$ knockout cells, they found significantly enhanced activity of Cdk2, resulting in increased proliferation [30]. In this study, the decreased methylation level in promoter region of C/ebpa-2 gene in chondrocytes may cause overproduction of C/ebp $\alpha-2$, thereby inhibiting Cdk2 activity and chondrocyte proliferation. However, we also detected a lower level of methylation in the promoter region of Cdk2 gene. This may be compensation to the inhibition of Cdk2 activity, which would increase Cdk2 expression to attenuate the inhibitory effect of C/ebp $\alpha-2$.

It has also been reported that changes in the time of expression and activity of Cdk2 are associated with cell apoptosis [31]. The relative expression level of cyclins varies according to specific phases of cell cycle. Cyclin $\mathrm{E}$ is highly expressed in G1/S phase, while cyclin B is highly expressed in $M$ phase in normal cells. However, in apoptotic cells cyclin B can also be detected in G1 phase, and likely, other cyclins can be detected out of their specific phases. This alteration may be associated

Table 2 Quantitative analysis of immunohistochemistry and TUNNEL staining

\begin{tabular}{llll}
\hline Staining & \multicolumn{2}{l}{ Positive rate (\%) } & P value \\
\cline { 2 - 3 } & Sham group & KOA group & \\
\hline BAX & $46.53 \pm 3.86$ & $88.62 \pm 5.49$ & 0.000 \\
BCL-2 & $70.77 \pm 7.61$ & $85.99 \pm 2.96$ & 0.032 \\
FAS & $62.10 \pm 1.68$ & $89.77 \pm 2.68$ & 0.000 \\
TUNNEL & $50.65 \pm 12.60$ & $83.12 \pm 13.79$ & 0.040 \\
\hline
\end{tabular}

with the overexpression of Cdks [32], implying that cyclins and Cdks have other functions than that in cell cycling in apoptotic cells. In this study, the decreased methylation of Cdk2 in chondrocytes may cause overexpression of $\mathrm{Cdk} 2$, inducing abnormal activation of cyclins and resulting in failure of mitosis and finally apoptosis. In fact, there is report that apoptosis is a form of mitosis failure [33].

The apoptosis of chondrocytes in KOA is also mediated by the Fas/FasL death receptor pathway or Bak-induced mitochondrial mechanism [34]. Fas binds to its ligand FasL to activate the tyrosine kinase, inducing phosphorylation of intracellular serine/threonine, finally leading to DNA cleavage and cell apoptosis [35, 36]. Fas can also induce cell apoptosis by indirectly activating triphosphate inositol and diglycerides, which then cause a rapid calcium release from the endoplasmic reticulum into cytoplasm and an influx of extracellular calcium, resulting in DNA breakage and chromosome shrinkage, and finally

Table 3 Methylation rate in the promoter region of selected genes

\begin{tabular}{llll}
\hline $\begin{array}{l}\text { Target genes } \\
\text { (distance to the } \\
\text { initiationcodon) }\end{array}$ & $\begin{array}{l}\text { sham group } \\
\text { Methylation rate } \\
\text { (mean } \pm \text { SD) }\end{array}$ & KOA group & $P$ value \\
\hline C/ebpa-2 (-452 bp) & $0.01096 \pm 0.0043$ & $0.002572 \pm 0.0024$ & 0.005 \\
Cdk2 (-55 bp) & $0.013573 \pm 0.0052$ & $0.004166 \pm 0.0030$ & 0.008 \\
Bak1 (6452 bp) & $0.026212 \pm 0.0139$ & $0.007123 \pm 0.0058$ & 0.022 \\
Fas & $0.958532 \pm 0.0063$ & $0.944658 \pm 0.0096$ & 0.047 \\
\hline
\end{tabular}




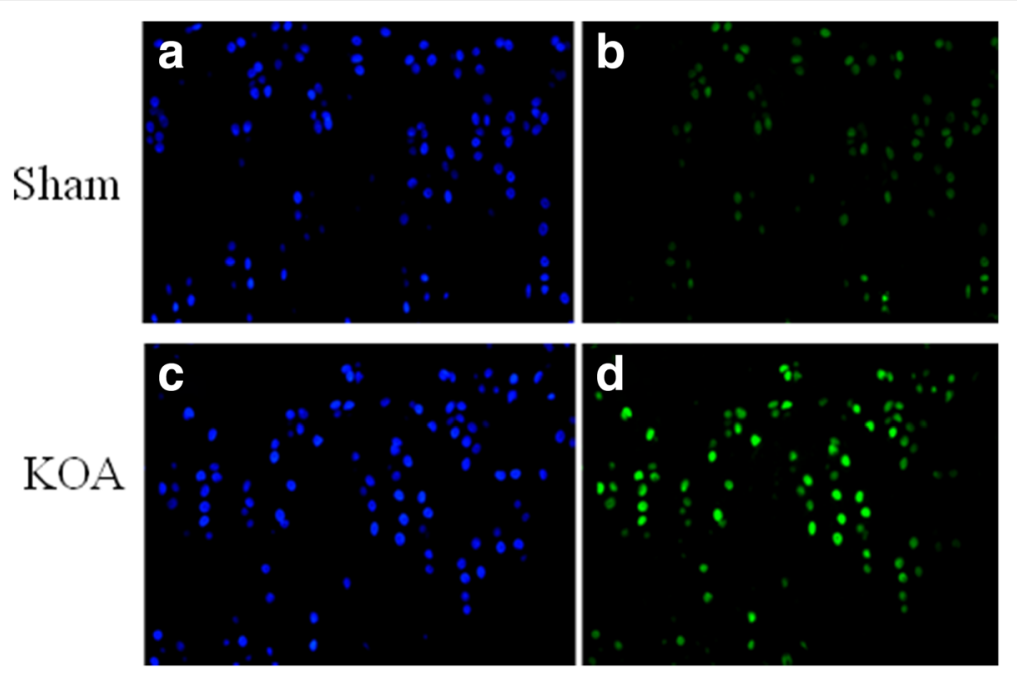

Fig. 5 TUNEL staining of the knee joint. a and $\mathbf{c}$, nuclei of chondrocyte; $\mathbf{b}$ and $\mathbf{d}$, nuclei of apoptotic cells

cell apoptosis [37]. Bak (Bcl-2 homologous antagonist/ killer) is a member of Bcl-2 gene family, but with a contrast function of promoting cell apoptosis [36, 38, 39]. Machner et al. found that the expression of Fas mRNA in KOA patients was significantly higher than that in the control group by quantitative PCR [11]. Karaliotas et al. reported a notable overexpression of median mRNA levels of BAX was also observed in patients with stage III KOA compared with the control, while the BCL2/BAX ratio was markedlydecreased [40].Płucienniket al.found that the $\mathrm{BCL} 2 / \mathrm{BAX}$ ratiomay regulate the gene promoter methylation [41]. Accumulating evidence has shown

\section{a}

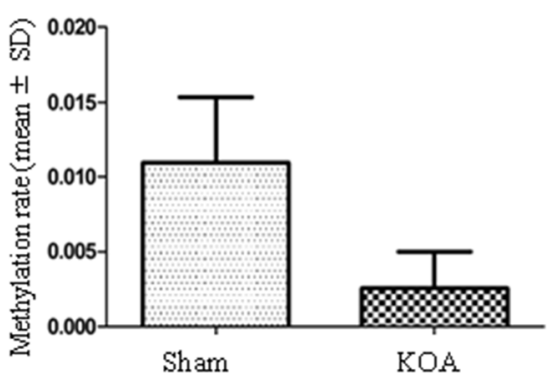

Clebpa-2 within a CpG island $-452 \mathrm{bp}$ to the initiation codon

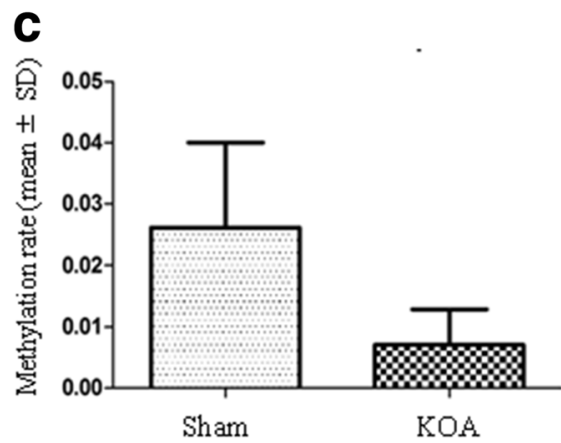

Bak1 within a CpG island 6452bp

to the initiation codon b

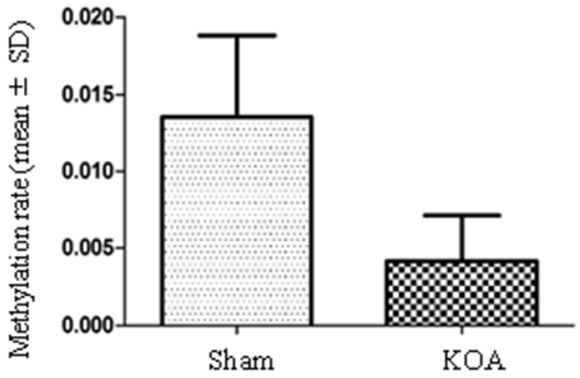

Cdk2 within a $\mathrm{CpG}$ island $-55 \mathrm{bp}$

to the initiation codon

d

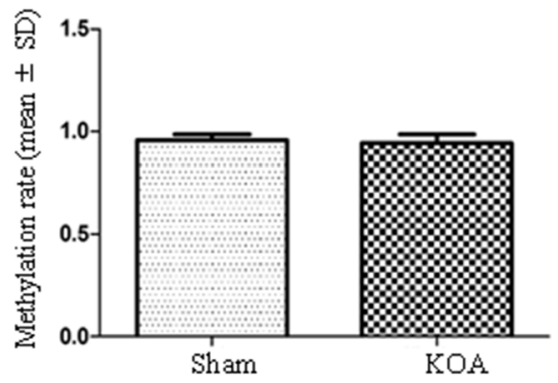

Fas within $\mathrm{CpG}$ islands on Chromosome 1

Fig. 6 Methylation rate in the promoter region of C/ebpa (a), Cdk2 (b), Bak1 (c), and Fas (d) 
overproduction of pro-apoptotic factors like Fas and Bak in KOA chondrocytes, which causes increased cell apoptosis, while targeted inhibition of these factors reduces apoptosis [42-44]. Consistently, in this study we found increased expression of Fas, Bax and $\mathrm{Bcl}-2$ in the KOA group than in the sham group using immunohistochemistry, and lower methylation levels in the promoter region of Fas and Bak1, which may induce their overexpression, thereby both leading to chondrocyte apoptosis. However, methylation in the promoter region of Fas genedid not play a key rolein the regulation at the level of its transcription, as the difference of the methylation of Fas gene between Sham and KOA groups was very slight. Li et al. reported that the transcription factors GA-binding protein (GABP) and activating protein-1 (AP-1) play a critical role in the induction of Fas mRNA [45]. Ryu et al.also found that Fas expression is transcriptionally induced by hypoxia-inducible factor (HIF)-2 $\alpha$ [35]. In future, we will further study the transcriptional regulation of Fas gene by the transcription factors.

\section{Conclusion}

To sum up, genetic aberrations are involved in KOA. Apoptosis of chondrocytes is a major pathological event in KOA pathogenesis and progression. Cartilage degeneration is attributed to multiple rather than a single risk factor. Findings in this study suggest that decreased methylation in promoter region of $\mathrm{C} / \mathrm{ebp} \alpha, \mathrm{Cdk} 2$, Fas, and Bak1 participates in the pathogenesis of $\mathrm{KOA}$, but the underlying mechanisms and pathways involved remain to be determined.

\section{Abbreviations \\ ABH/OG staining: Alcin blue/Orange G staining; Bak: Bcl-2 Homologous antagonist/killer; BCl-2: B-cell lymphoma-2; C/ebpa: CCAAT/enhancer binding protein a; Cdk: Cyclin dependent kinase; EDTA: Ethylene DiamineTetraacetic Acid; Fas: Factor associated suicide; HE staining: Haematoxylin \& eosin staining; KOA: Knee osteoarthritis; TUNNEL: Terminal-deoxynucleotidyltransferase mediated nick end labeling}

\section{Acknowledgements}

We would like to thank for the person who gave assistance to this study.

\section{Funding}

This work was supported by the Three-Year Plan to Accelerate the Development of Chinese Medicine in Shanghai (ZY3-CCCX-3-3011, ZY3-LCPT-2-2003), the Twelfth Five-Year Key Project of the National Administration of Traditional Chinese Medicine; National Natural Science Foundation of China (81473701), and a project of Shanghai Key Laboratory of Geriatrics (13dz2260700).

\section{Availability of data and materials}

Summarized data have been presented in this manuscript. Raw data for this study are located and protected at Fudan University. Sharing of the raw data is not possible, because a secondary analysis is planned.

\section{Authors' contributions}

XXW, PS, and HX performed the experiments and are responsible for data acquisition. HFQ and TW performed data analysis. DZT and XG are responsible for the conception and design of the study. DZT and XG drafted the article, and revised it critically for important intellectual content. All authors have participated actively in carrying out and improving the study and all have approved the submission of this article.

\section{Ethics approval and consent to participate}

This study was approved by the Ethics Committee of Shanghai University of Traditional Chinese Medicine, China (No: SZY201507001). All procedures were in compliance with ethical guidelines for animal experiments. All efforts were made to minimize animal suffering.

\section{Consent for publication}

Not applicable

\section{Competing interests}

The authors declare that they have no competing interest with other people or any organizations.

\section{Publisher's Note}

Springer Nature remains neutral with regard to jurisdictional claims in published maps and institutional affiliations.

Received: 4 April 2017 Accepted: 25 August 2017

Published online: 31 August 2017

References

1. Crane DM, Oliver KS, Bayes MC. Orthobiologics and knee osteoarthritis: a recent literature review, treatment algorithm, and Pathophysiology discussion. Phys Med RehabilClin N Am. 2016;27(4):985-1002.

2. Reynard LN. Analysis of genetics and DNA methylation in osteoarthritis: what have we learnt about the disease? Semin Cell Dev Biol. 2017;62:57-66.

3. Xu YS, Jiang XJ, Chen JM. A single nucleotide polymorphism of AIRE gene located in the 21q22.3 increases the risk of rheumatoid arthritis. Oncotarget. 2017, published online. doi:10.18632/oncotarget.17746.

4. Shao L, Fujii H, Colmegna I, et al. Deficiency of the DNA repair enzyme ATM in rheumatoid arthritis. J Exp Med. 2009;206(6):1435-49.

5. Liang M, Russell G, Hulley PA. Bim, Bak, and Bax regulate osteoblast survival. J Bone Miner Res. 2008;23(5):610-20.

6. Lin MN, Liu XX, Wang SL, et al. Effect of OA kneepad on apoptosis genes $\mathrm{BCl}-2$ and p53 expression in articular cartilage cells of experimental knee osteoarthritis. Zhongguo Gu Shang. 2009;22(9):688-91.

7. Megyesi J, Tarcsafalvi A, Seng N, et al. Cdk2 phosphorylation of BCl-xL after stress converts it to a pro-apoptotic protein mimicking Bax/Bak. Cell Death Discov. 2016;2:15066.

8. Roach HI, Aigner T. DNA methylation in osteoarthritic chondrocytes: a new molecular target. Osteoarthr Cartil. 2007;15(2):128-37.

9. Okada Y, Wu D, Trynka G, et al. Genetics of rheumatoid arthritis contributes to biology and drug discovery. Nature. 2014;506(7488):376-81.

10. Lv H, Ma X, Che T, et al. Methylation of the promoter a of estrogen receptor alpha gene in hBMSC and osteoblasts and its correlation with homocysteine. Mol Cell Biochem. 2011;355(1-2):35-45.

11. Machner A, Baier A, Wille A, et al. Higher susceptibility to Fas ligand induced apoptosis and altered modulation of cell death by tumor necrosis factor-alpha in periarticular tenocytes from patients with knee joint osteoarthritis. Arthritis Res Ther. 2003;5(5):R253-61.

12. Lee $\mathrm{YH}$, Bae SC. Intercellular adhesion molecule-1 polymorphisms, K469E and G261R and susceptibility to vasculitis and rheumatoid arthritis: a metaanalysis. Cell Mol Biol (Noisy-le-grand). 2016;62(12):84-90.

13. Kurreeman FA, Stahl EA, Okada Y, et al. Use of a multiethnic approach to identify rheumatoid- arthritis-susceptibility loci, 1p36 and 17q12. Am J Hum Genet. 2012;90(3):524-32.

14. Sakao K, Takahashi KA, Arai Y, et al. Osteoblasts derived from osteophytes produce interleukin-6, interleukin-8, and matrix metalloproteinase-13 in osteoarthritis. J Bone Miner Metab. 2009;27(4):412-23.

15. Reynard LN, Loughlin J. Genetics and epigenetics of osteoarthritis. Maturitas. 2012;71(3):200-4.

16. Taniguchi T, Ogasawara K, Takaoka A, et al. IRF family of transcription factors as regulators of host defense. Annu Rev Immunol. 2001;19:623-55.

17. Ye L, Fan Z, Yu B, et al. Histone demethylases KDM4B and KDM6B promotes osteogenic differentiation of human MSCs. Cell Stem Cell. 2012;11(1):50-61.

18. Zhang Y, Ma C, Liu X, et al. Epigenetic landscape in PPARY2 in the enhancement of adipogenesis of mouse osteoporotic bone marrow stromal 
cell. Biochimica et Biophysica Acta (BBA) - Mol Basis Dis. 2015;1852(11): 2504-16.

19. Baker EK, Taylor S, Gupte A, et al. Wnt inhibitory factor 1 (WIF1) is a marker of osteoblastic differentiation stage and is not silenced by DNA methylation in osteosarcoma. Bone. 2015;73:223-32.

20. Hulth A, Lindberg L. TelhagH. Experimental osteoarthritis in rabbits. Preliminary report. ActaOrthop Scand. 1970;41(5):522-30.

21. Feng $\mathrm{H}$, Conneely KN, Wu H. A Bayesian hierarchical model to detect differentially methylated loci from single nucleotide resolution sequencing data. Nucleic Acids Res. 2014;42(8):e69.

22. Paul DS, Guilhamon P, Karpathakis A, et al. Assessment of RainDrop BS-seq as a method for large-scale, targeted bisulfite sequencing. Epigenetics. 2014;9(5):678-84.

23. Kim HA, Blanco FJ. Cell death and apoptosis in osteoarthritic cartilage. Curr Drug Targets. 2007;8(2):333-45.

24. Araki S, Imai S, Ishigaki $H$, et al. Improved quality of cartilage repair by bone marrow mesenchymal stem cells for treatment of an osteochondral defect in a cynomolgus macaque model. ActaOrthop. 2015;86(1):119-26.

25. Friedman AD. C/EBPalpha in normal and malignant myelopoiesis. Int J Hematol. 2015;101(4):330-41.

26. Zhao XY, Chen XY, Zhang ZJ, et al. Expression patterns of transcription factor PPARgamma and C/EBP family members during in vitro adipogenesis of human bone marrow mesenchymal stem cells. Cell Biol Int. 2015;39(4): 457-65.

27. Sun L, Huang Y, Wei Q, et al. Cyclin E-CDK2 protein phosphorylates plant homeodomain finger protein 8 (PHF8) and regulates its function in the cell cycle. J Biol Chem. 2015;290(7):4075-85.

28. Chauhan S, Diril MK, Lee JH, et al. Cdk2 catalytic activity is essential for meiotic cell division in vivo. Biochem J. 2016;473(18):2783-98.

29. Oakes $V$, Wang W, Harrington B, et al. Cyclin a/Cdk2 regulates $C d h 1$ and claspin during late S/G2 phase of the cell cycle. Cell Cycle. 2014;13(20):3302-11.

30. Wang $H$, lakova $P$, Wilde $M$, et al. C/EBPalpha arrests cell proliferation through direct inhibition of Cdk2 and Cdk4. Mol Cell. 2001;8(4):817-28.

31. Roset R, Gil-Gomez G. Measurement of changes in Cdk2 and cyclin oassociated kinase activity in apoptosis. Methods Mol Biol. 2009;559:161-72.

32. Golsteyn RM. Cdk1 and Cdk2 complexes (cyclin dependent kinases) in apoptosis: a role beyond the cell cycle. Cancer Lett. 2005;217(2):129-38.

33. Vakifahmetoglu $\mathrm{H}$, Olsson M, Zhivotovsky B. Death through a tragedy: mitotic catastrophe. Cell Death Differ. 2008;15(7):1153-62.

34. Hwang HS, Kim HA. Chondrocyte apoptosis in the pathogenesis of osteoarthritis. Int J Mol Sci. 2015;16(11):26035-54.

35. Ryu JH, Shin $Y$, Huh $Y H$, et al. Hypoxia-inducible factor-2alpha regulates Fasmediated chondrocyte apoptosis during osteoarthritic cartilage destruction. Cell Death Differ. 2012;19(3):440-50.

36. Musumeci G, Castrogiovanni P, Trovato FM, et al. Biomarkers of Chondrocyte apoptosis and Autophagy in osteoarthritis. Int J Mol Sci. 2015; 16(9):20560-75.

37. Lu Q, Wu Z, Li D. Single cell analysis of $\mathrm{H}(2) \mathrm{O}(2)$ mediated Fas mRNA expression and ca (2+) influx in LO (2) cells. Zhonghua Yi XueZaZhi. 2000; 80(3):210-3

38. Falah $M$, Najafi $M$, Houshmand $M$, et al. Expression levels of the BAK1 and BCL2 genes highlight the role of apoptosis in age-related hearing impairment. Clinlnterv Aging. 2016:11:1003-8.

39. Lindqvist $L M$, Vaux $D L$. BCL2 and related prosurvival proteins require BAK1 and BAX to affect autophagy. Autophagy. 2014;10(8):1474-5.

40. Karaliotas Gl, Mavridis K, Scorilas A, et al. Quantitative analysis of the mRNA expression levels of BCL2 and BAX genes in human osteoarthritis and normal articular cartilage: an investigation into their differential expression. Mol Med Rep. 2015;12(3):4514-21.

41. Płuciennik E, Nowakowska M, Wujcicka Wl, et al. Genetic alterations of WWOX in Wilms' tumor are involved in its carcinogenesis. Oncol Rep. 2012;28(4):1417-22.

42. Tu Y, Xue H, Xia Z, et al. Effect of different concentrations of dexamethasone on apoptosis and expression of Fas/FasL in human osteoarthritis chondrocytes. ZhongguoXiu Fu Chong JianWaiKeZaZhi. 2012;26(5):536-41.

43. Sezgin M, Barlas IO, Yildir S, et al. Apoptosis-related Fas and FasL gene polymorphisms' associations with knee osteoarthritis. Rheumatol Int. 2013;33(8):2039-43.

44. Diaz-Gallo LM, Garcia S, Ortego-Centeno N, et al. Association study of BAK1 gene polymorphisms in Spanish rheumatoid arthritis and systemic lupus erythematosus cohorts. Ann RheumDis. 2012;71(2):314-6.
45. Li XR, Chong AS, Wu J, et al. Transcriptional regulation of Fas gene expression by GA-binding protein and AP-1 in T cell antigen receptor.CD3 complex-stimulated T cells. J Biol Chem. 1999;274(49):35203-10.

\section{Submit your next manuscript to BioMed Central and we will help you at every step:}

- We accept pre-submission inquiries

- Our selector tool helps you to find the most relevant journal

- We provide round the clock customer support

- Convenient online submission

- Thorough peer review

- Inclusion in PubMed and all major indexing services

- Maximum visibility for your research

Submit your manuscript at www.biomedcentral.com/submit
Biomed Central 